\title{
Analisa Stabilitas Lereng dan Alternatif Penanganannya Studi Kasus Proyek Pekerjaan Kanal Utama Row 80 Kawasan Industri JIIPE-Gresik
}

\author{
Aan Fauzi ${ }^{1{ }^{*},}$, Sukobar ${ }^{1}$, Dicky Imam Wahyudi ${ }^{1}$, R.A. Triaswati Moeljono ${ }^{1}$ \\ Departemen Teknik Infrastuktur Sipil, Institut Teknologi Sepuluh Nopember, Surabaya ${ }^{1}$ \\ Koresponden*, Email: aanfauzi@its.ac.id
}

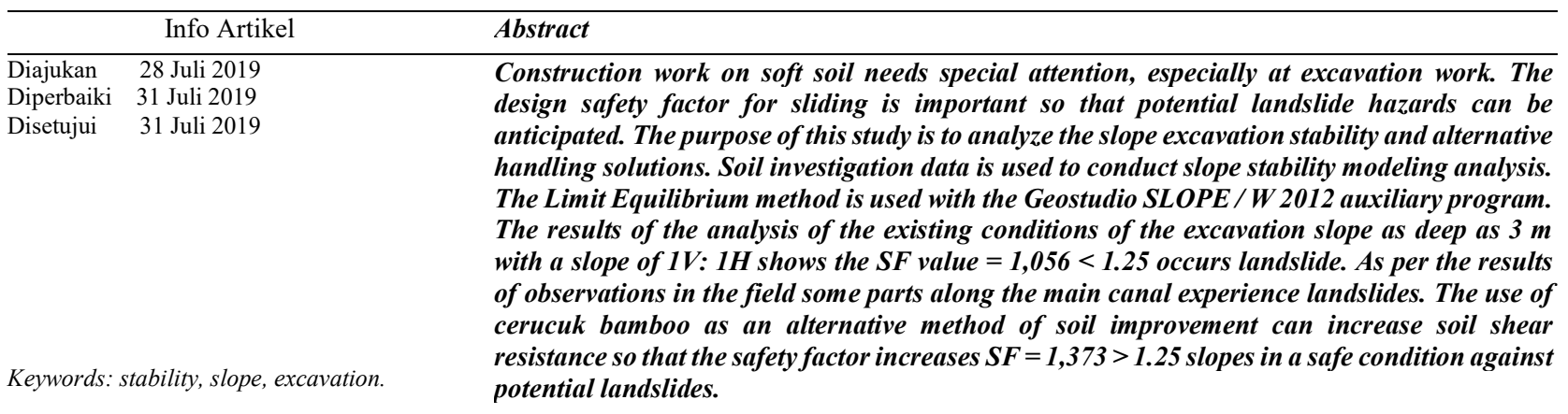

Abstrak

Pekerjaan konstruksi pada tanah lunak perlu diperhatian khusus terutama pada pekerjaan galian. Faktor keamanan desain terhadap sliding penting dipersyaratkan sehingga bahaya potensi longsor bisa diantisipasi. Tujuan dari penelitian ini adalah untuk menganalisa stabilitas lereng galian dan alternati solusi penanganan. Data penyelidikan tanah digunakan untuk melakukan analisa pemodelan kestabilan lereng. Digunakan metode Limit Equilibrium dengan program bantu Geostudio SLOPE/W 2012. Hasil analisa kondisi eksisting lereng galian sedalam $3 \mathrm{~m}$ dengan kemiringan lereng $1 \mathrm{~V}: 1 \mathrm{H}$ menunjukan nilai $\mathrm{SF}=1.056<1.25$ terjadi kelongsoran. Sesuai hasil pengamatan dilapangan beberapa bagian sepanjang kanal utama mengalami kelongsoran. Penggunaan cerucuk bambu sebagai alternatif metode perbaikan tanah mampu meningkatkan tahanan geser tanah shingga

Kata kunci: stabilitas, lereng, galian faktor keamanan meningkat $\mathrm{SF}=1.373>1.25$ lereng dalam kondisi aman terhadap potensi longsor.

\section{Pendahuluan}

Kawasan industri JIIPE berada di Gresik Jawa Timur, area terletak pada lahan bekas rawa-rawa dan tambak. Tanah dasar diarea tersebut berjenis tanah lempung lunak. Tanah lunak adalah tanah yang memiliki kuat geser undrained lapangan kurang dari $40 \mathrm{kPa}$ dan kompresibilitas tinggi [1]. Kondisi seperti ini memerlukan perhatian khusus terhadap kontruksi di atasnya.

Perencanaan galian kanal utama sedalam $3 \mathrm{~m}$ dengan kemiringan lereng $1 \mathrm{~V}: 1 \mathrm{H}$. Berdasarkan pengamatan kondisi visual, lereng galian mengalami kelongsoran, pergerakan tanah pada lereng seperti pada Gambar 1, Gambar 2 dan Gambar 3. Masalah mendasar yang ditemukan berdasarkan survey lapangan adalah kelongsoran terjadi pada beberapa lokasi galian sepanjang $500 \mathrm{~m}$ dan tidak adanya perkuatan lereng galian.

Untuk menentukan metode perbaikan dan perkuatan lereng yang tepat, diperlukan suatu analisis stabilitas lereng.
Analisis ini berguna untuk mendukung perancangan yang aman dan ekonomis dari lereng tersebut. Untuk itu, pada lokasi open canal perlu dilakukan analisis stabilitas lereng dan alternatif penanganannya.

\section{Metode}

Perbaikan stabilitas lereng umumnya dilakukan untuk mereduksi gaya-gaya yang menggerakkan, menambah tahanan geser tanah atau keduanya. Gaya-gaya yang menggerakkan dapat direduksi dengan cara:

a. Menggali material yang berada pada zona tidak stabil.

b. Mengurangi tekanan air pori dengan mengalirkan air pada zona tidak stabil.

Macam-macam metode perbaikan lereng, antara lain adalah:

a. Merubah geometri lereng

b. Mengontrol drainase dan rembesan

c. Pembuatan struktur untuk stabilisasi 
d. Pembongkaran dan pemindahan

e. Perlindungan permukaan lereng

Analisa stabilitas lereng menggunakan metoda keseimbangan batas (Limit Equilibrium Method, LEM) dengan software bantu Geostudio SLOPE/W 2012. Analisa dengan metode limit equilibrium ini biasa digunakan untuk mengkaji apakah lereng tanah berpotensi mengalami kelongsoran apa tidak. Potensi stabilitas lereng terhadap kelongsoran dinyatakan dengan nilai faktor keamanan (SF). Faktor keamanan lereng yang disyaratkan untuk analisis kestabilan lereng tanah diperlihatkan pada Tabel 1 dengan didasarkan pada pertimbangan biaya dan konsekuensi kegagalan lereng terhadap tingkat ketidakpastian kondisi analisis. Dalam hal ini nilai faktor keamanan dipersyaratkan $\mathrm{SF} \geq 1.25$ [2].

Lereng sesuai perencanaan dianalisa kondisi eksisting untuk mengetahui nilai faktor keamanan, dari analisa awal dapat diketahui apakah lereng berpotensi mengalami kelongsoran atau tidak. Dari analisa awal direncanakan alternatif perbaikan untuk kondisi lereng yang longsor, metode perbaikan dimaksudkan untuk menambah gaya-gaya yang menahan kelongsoran. Hal ini dilakukan dengan cara meletakkan masa tanah/batuan di kaki lereng dan pembuatan struktur untuk stabilisasi berupa cerucuk bambu.

Cerucuk merupakan suatu metode perbaikan tanah yang sering dijumpai guna meningkatkan daya dukung pada tanah yang lunak maupun sebagai penguat lereng timbunan. Cerucuk bisa berupa tiang kayu berukuran panjang 4-6 meter dengan diameter $10 \mathrm{~cm}$. Pada tanah lunak yang lebih dalam bisa berupa tiang beton. Bila kapasitas daya dukung beban yang lebih besar diperlukan, penggunaan dari tiang beton pra cetak lebih cocok. Tiang pra cetak berbentuk persegi atau segi tiga dengan sisi berukuran 10-40 cm, akan memberikan kapasitas daya dukung yang cukup besar [3].

Penggunaan cerucuk dimaksudkan untuk menaikkan tahanan geser tanah. Pada saat tanah mengalami gaya geser maka gaya penahan yang diberikan tanah hanya begantung pada nilai kohesi dan sudut geser dalam tanah. Pada kasus tanah lunak tahanan geser hanya ditahan oleh nilai kohesi disepanjang bidang gelincir. Setelah ditambahan cerucuk, tahanan geser tidak hanya dipikul oleh kohesi tanah saja namun ada tambahan gaya dari cerucuk $(\mathrm{P})$, sehingga kekuatan geser tanah meningkat [4]. Skema peningkatan kuat geser tanah dengan cerucuk bisa dilihat pada Gambar 4.

Analisis stabilitas lereng harus mempertimbangkan beban hidup (live load), mati (dead load) dan gempa sesuai peruntukan lereng galian dan timbunan. Beban tambahan (sur- charge load) $10 \mathrm{kN} / \mathrm{m}^{2}$ harus diterapkan untuk memperhitungkan beban yang bekerja pada permukaan atas lereng kecuali ada persyaratan lain sesuai peruntukannya [2].

Tabel 1. Nilai faktor keamanan untuk lereng tanah

\begin{tabular}{lcc}
\hline \multirow{2}{*}{$\begin{array}{l}\text { Biaya dan konsekuensi dari } \\
\text { kegagalan lereng }\end{array}$} & $\begin{array}{c}\text { Tingkat ketidak } \\
\text { pastian kondisi } \\
\text { analisis }\end{array}$ \\
\cline { 2 - 3 } & $\begin{array}{c}\text { Rendah }^{\mathrm{a}} \\
\text { Tinggi }\end{array}$ \\
\hline $\begin{array}{l}\text { Biaya perbaikan sebanding dengan } \\
\text { biaya tambahan untuk merancang }\end{array}$ & 1,25 & 1,5 \\
lereng yang lebih konservatif & \\
Biaya perbaikan lebih besar dari & 1,5 & 2,0 atau \\
biaya tambahan untuk merancang & lebih \\
lereng yang lebih konservatif & \\
a Tingkat ketidakpastian kondisi analisis dikategorikan \\
rendah, jika kondisi geologi dapat dipahami, kondisi tanah \\
seragam, penyelidikan tanah konsisten, lengkap dan logis \\
terhadap kondisi di lapangan. \\
b Tingkat ketidakpastian kondisi analisis dikategorikan \\
tinggi, jika kondisi geologi sangatn kompleks, kondisi \\
tanah bervariasi, dan penyelidikan tanah tidak konsisten \\
dan tidak dapat diandalkan
\end{tabular}

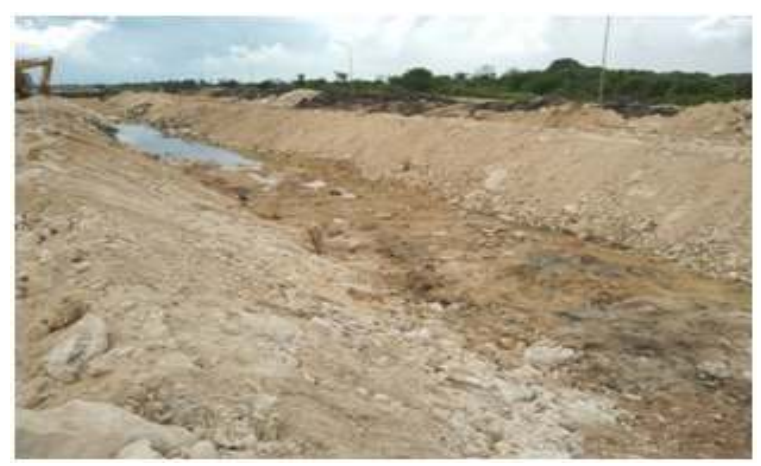

Gambar 1. Kondisi visual lereng sebelum longsor

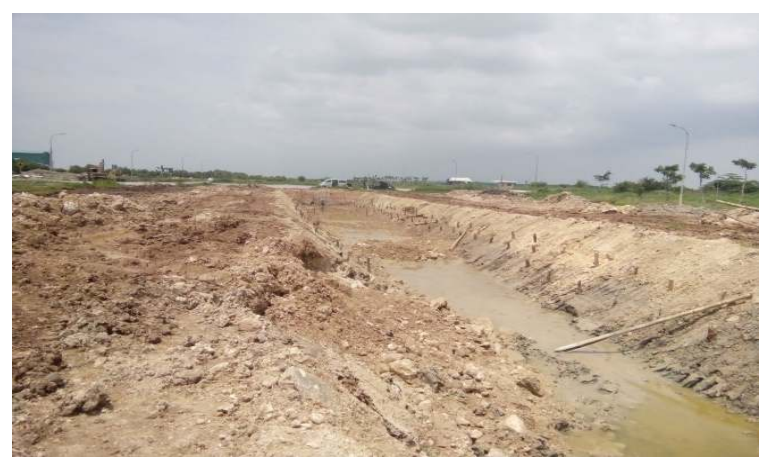

Gambar 2. Kondisi kelongsoran lereng 


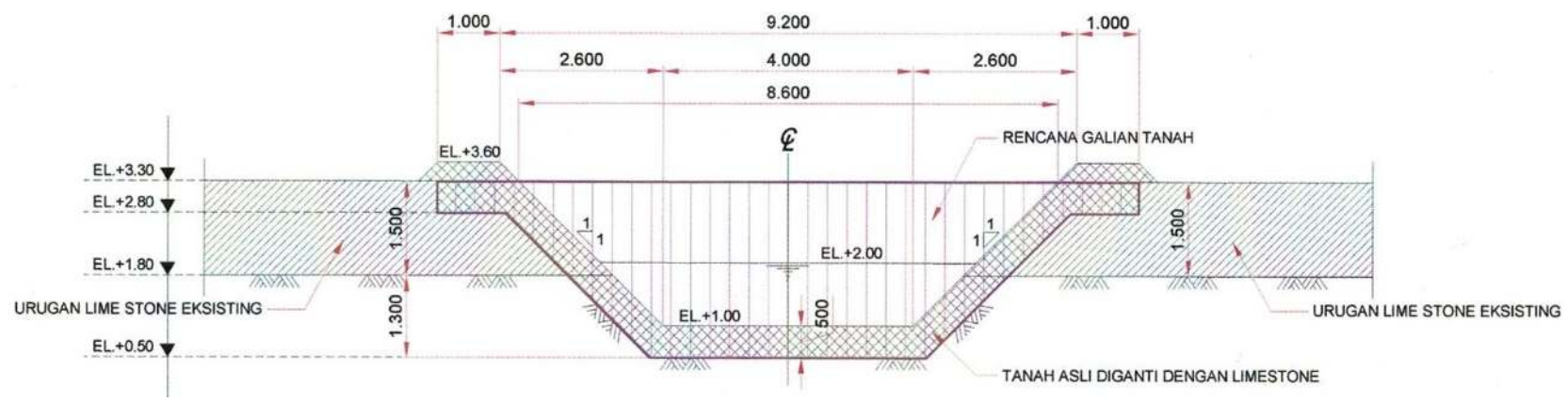

(c)

Gambar 3. Perencanaan Kanal Utama.

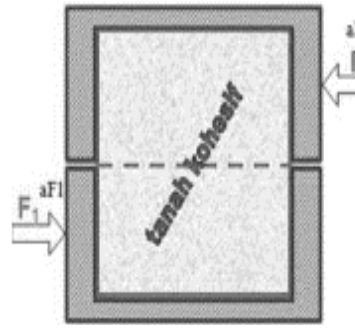

Saat geser:

$\mathrm{F}_{1}=\mathrm{Cu} \times \mathrm{A}$
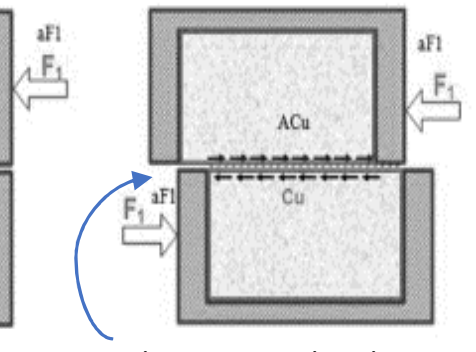

Tahanan geser kondisi undrained $=\mathrm{Cu}$

Tahanan geser tanah, $\tau=\mathrm{Cu}+\sigma \mathrm{n} \tan \phi \rightarrow \tau=\mathrm{Cu}$
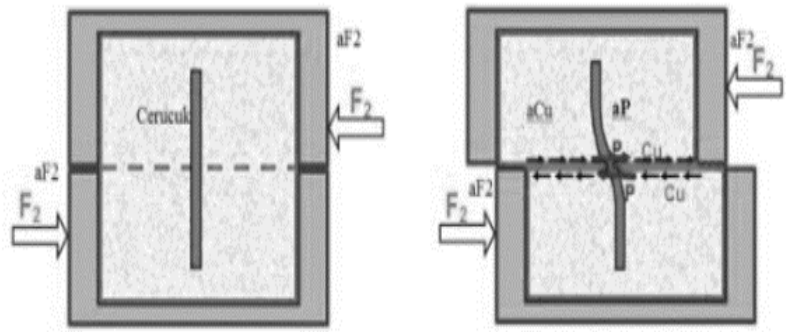

Saat geser:

$F_{2}=\mathrm{Cu} \times \mathrm{A}+\mathrm{P}$

Gambar 4. Skema Peningkatan Tahanan Geser Tanah Akibat Cerucuk

Sumber: Noor Endah Mochtar [4]

\section{Hasil dan Pembahasan}

Data hasil penyelidikan tanah dilokasi menunjukan kondisi tanah dasar berupa lapisan tanah lempung lunak. Parameter tanah lempung lunak yang digunakan disajikan pada Tabel 2.

Material limestone digunakan untuk perbaikan tanah dasar dan menambah massa tanah di kaki lereng. Parameter timbunan yang digunakan:

- Berat isi : $\gamma=18.53 \mathrm{kN} / \mathrm{m}^{3}$

- Kohesi : $\mathrm{c}=2 \mathrm{kN} / \mathrm{m}^{2}$
- Sudut geser dalam : $\phi=35^{\circ}$

Material bambu digunakan untuk cerucuk. Parameter bambu yang digunakan disajikan pada Tabel 3.

Tabel 2. Parameter Tanah Dasar

\begin{tabular}{cccccc}
\hline \multicolumn{2}{c}{ Kedalaman (m) } \\
Dari & Sampai & Jenis Tanah & $\begin{array}{c}\mathrm{Cu} \\
\mathrm{kN} / \mathrm{m}^{2}\end{array}$ & $\begin{array}{c}\text { Phi } \\
\left(^{\circ}\right)\end{array}$ & $\begin{array}{c}\text { Berat } \\
\text { isi } \\
\left(\mathrm{kN} / \mathrm{m}^{3}\right)\end{array}$ \\
\hline 0 & 10 & $\begin{array}{l}\text { Lempung } \\
\text { lunak }\end{array}$ & 7 & 1 & 16.0 \\
\hline
\end{tabular}

Tabel 3. Parameter Bambu Sebagai Cerucuk

\begin{tabular}{cccccc}
\hline $\begin{array}{c}\text { Diameter } \\
\mathrm{cm}\end{array}$ & $\begin{array}{c}\mathrm{W} \\
\mathrm{kg} / 6 \mathrm{~m}\end{array}$ & $\begin{array}{c}\text { Mcrack } \\
\mathrm{kN} . \mathrm{m}\end{array}$ & $\begin{array}{c}\text { EA } \\
\mathrm{kN}\end{array}$ & $\begin{array}{c}\text { EI } \\
\mathrm{Kn} . \mathrm{m}^{2}\end{array}$ & $\mathrm{v}$ \\
\hline 11 & 25 & 10.0 & 28000 & 35.7 & 0.30 \\
\hline Sumber: Helmy darjanto et al. $[3]$ & & &
\end{tabular}

Geometri pemodelan analisa stabilitas lereng galian seperti pada Gambar 5.

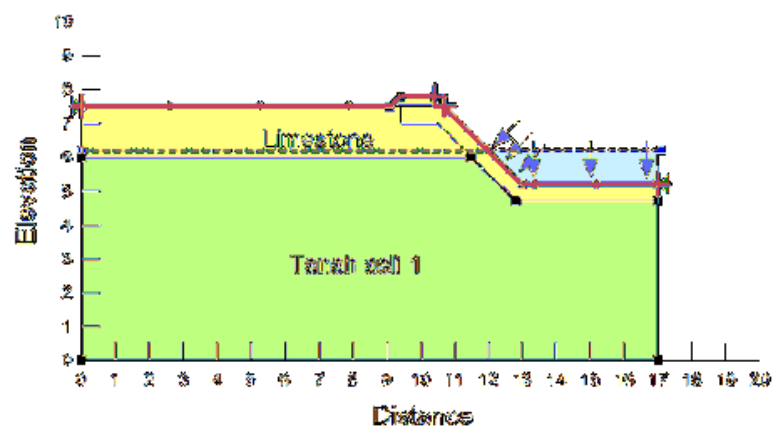

Gambar 5. Profil Bidang Analisa Sesuai Crossection A-A

Hasil analisa faktor keamanan lereng galian menunjukan nilai $\mathrm{SF}=1.056<1.25$, yang artinya lereng berada dalam 
kondisi berpotensi longsor. Sesuai hasil pengamatan dilapangan beberapa bagian sepanjang open canal mengalami kelongsoran.

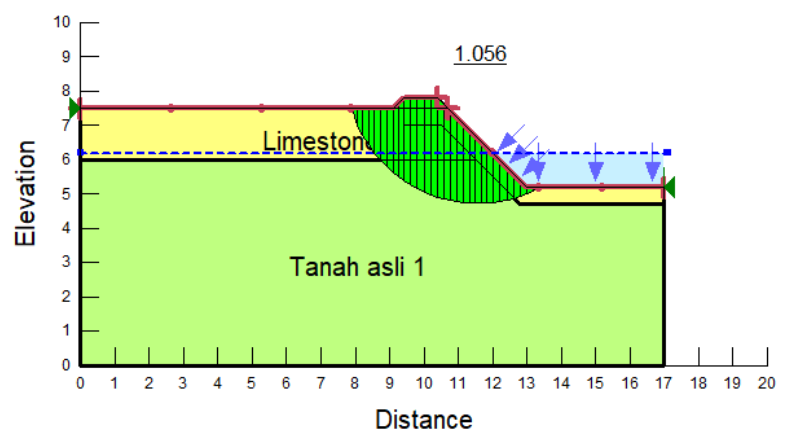

Gambar 6. Analisa Stabilitas Lereng Eksisting $\mathrm{SF}=1,056$

Perbaikan stabilitas lereng galian dengan memasang 1 cerucuk bambu dengan jarak pemasangan $1 \mathrm{~m}$ dan panjang 3 m pada kaki timbunan. Hasil analisa menunjukan nilai faktor keamanan meningkat menjadi $\mathrm{SF}=1.193$ namun masih lebih kecil dari 1.25 , yang artinya lereng masih berada dalam kondisi berpotensi longsor.

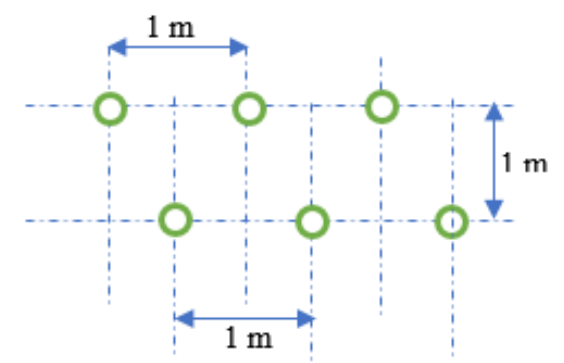

Gambar 7. Denah Pemasangan Cerucuk Bambu

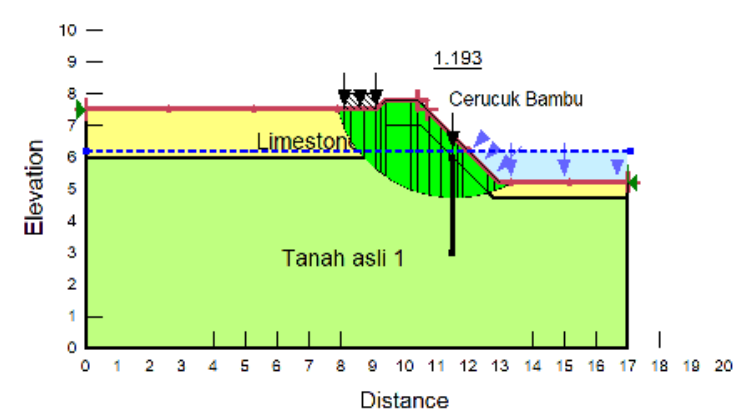

Gambar 8. Analisa Stabilitas Lereng Dengan 1 Cerucuk SF= 1,056

Penambahan jumlah cerucuk menjadi 2 baris zig-zag dengan jarak pemasangan $1 \mathrm{~m}$ dan panjang $3 \mathrm{~m}$ pada kaki timbunan.

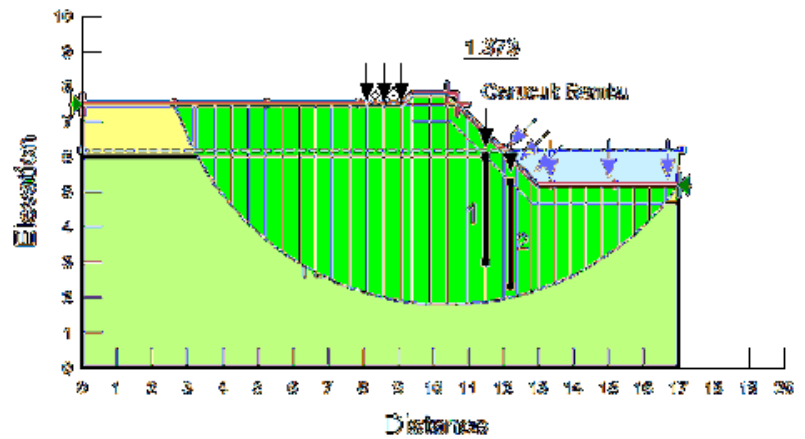

Gambar 9. Analisa Stabilitas Lereng Dengan 1 Cerucuk SF= 1,373

Hasil analisa menunjukan nilai faktor keamanan meningkat menjadi $\mathrm{SF}=1.373>1.25$ lereng dalam kondisi aman terhadap potensi longsor.

\section{Simpulan}

Analisa stabilitas lereng dengan menggunakan limit equilibrium method telah digunakan untuk menilai stabilitas lereng rencana Proyek Pekerjaan Kanal Utama Row 80 Di Kawasan JIIPE, Manyar, Gresik. Dengan kesimpulan sebagai berikut:

1. Faktor keamanan desain terhadap sliding penting dipersyaratkan, kondisi lereng eksisting mengalami longsor hasil analisa menunjukan nilai $\mathrm{SF}=1.056<1.25$.

2. Cerucuk bambu bisa digunakan sebagai alternatif cara untuk meningkatkan tahanan geser.

3. Hasil analisa pemasangan cerucuk bambu mampu meningkatkan nilai faktor keamanan $\mathrm{SF}=1.373>1.25$.

\section{Daftar Pustaka}

[1] Pusat Litbang Prasarana Transportasi, "Panduan Geoteknik 4: Timbunan Jalan pada Tanah Lunak: Disain dan Konstruksi,” Bandung, 2001.

[2] SNI:8460, Persyaratan perancangan geoteknik, Jakarta: Badan Standardisasi Nasional, 2017.

[3] H., Darjanto, "Penggunaan Bambu Untuk Mengatasi Sliding Pada Reklamasi Di Tanah Lunak," NEUTRON, vol. 4, no. 1, p. 39, Feb. 2004.

[4] Mochtar, Noor Endah, Modul Ajar Metode Perbaikan Tanah, Cetakan Pertama. Surabaya: ITS Press, 2012.

[5] G. T. Liong, and D. J. G. Herman, "Analisa Stabilitas Lereng Limit Equilibrium vs Finite Element Method," in HATTI Annual Scientific Meeting XVI, 2012. 